\title{
PEREMPUAN MUSLIMAH ODHA DI KEBUMEN: SEBUAH KAJIAN TRANSFORMASI AWAL
}

\author{
Agus Salim Chamidi \\ Institut Agama Islam Nabdlatul Ulama (LANU) Kebumen \\ email: aschamidi@yahoo.co.id
}

\begin{abstract}
This research is a transformative research for empowering women muslimab infected HIV AIDS and then they become persons living with HIV AIDS. In this research they are called as women muslimah living with HIV AIDS. Location of research is in Kebumen Central Java Indonesia. The research is qualitative, using model participatory action research (PAR) and technique in-depth interview, observation, and documentation, and gathered in model knowledge sharing and discussion participatory. Its key-informants are some women muslimah living with HIV AIDS in Kebumen. It is organized on May-June 2018. Although it is still on their planning phase, its results have made happy enough. The results are those: (1)women muslimab living with HIV AIDS realize and agree toward some efforts on reinforcing them through Islamic activity and productive economics activity, (2)the volunteers on HIV AIDS also support the efforts, (3)the women muslimah are still afraid on stigma and discrimination by open status so they need helps from the volunteers for assisting them closely, (4)there are plans for organizing on empowering women muslimab living with HIV AIDS, and (5)model PAR here is still recommended. Recommendation from the research is urgency of empowering management for women muslimab living with HIV AIDS massively and comprehensively by gathering stakeholders participatory.
\end{abstract}

Keyword: Women Muslimah with HIV AIDS, Transformation Research 


\section{PENDAHULUAN}

Tahun 2017, Kebumen menduduki peringkat pertama untuk kasus HIV AIDS di Provinsi Jawa Tengah. Sampai dengan Juni 2018 jumlah Orang Dengan HIV AIDS (ODHA) di Kebumen sebesar 1.049 orang, atau 89,2\% dari estimasi ODHA seluruhnya sebesar 1.176 orang ${ }^{1}$. Jumlah ini tersebar di 26 kecamatan di Kebumen, dimana 15 kecamatan terdapat kasus $>20$. Jumlah ODHA riil itu terdiri dari 649 laki-laki $(61,9 \%)$ dan 400 perempuan (39,1\%). Dari jumlah perempuan ODHA ini 394 beragama Islam (muslimab). Dari jumlah 394 perempuan muslimah ODHA, 222 orang berstatus sebagai ibu rumah tangga (IRT), atau sejumlah 56,3\%. Oleh karena itu perhatian khusus terhadap perempuan muslimah ODHA, khususnya yang berstatus IRT menjadi sangat urgen. Bagaimanapun persoalan kesehatan merupakan persoalan mendasar. Penanganan persoalan ODHA pun memerlukan keseriusan dan kontiunitas dari banyak pihak.

Persoalan terkait ODHA cukup banyak disorot dalam sejumlah kajian. Nurhasanah $\mathrm{dkk}^{2}$, misalnya, meneliti ODHA dalam kaitannya dengan konsep diri ODHA yang terstigma dan terdiskriminasi dari lingkungan sosialnya. Stigma dan diskriminasi sosial ternyata mengakibatkan konsep diri ODHA pun menjadi negatif terhadap diri ODHA sendiri. Riset Surahman Wahyu, dkk. ${ }^{3}$ di Sumatra Barat menunjukkan bahwa ODHA telah mengalami stigma dan diskriminasi sehingga konsep diri mereka pun mengalami rasa rendah diri dan perilaku serba salah. Sedangkan Awatiful Azza, dkk. ${ }^{4}$ dalam risetnya di Jember mencoba mendalami upaya pemberdayaan kesehatan dan ekonomi penderita HIV AIDS dengan menggunakan pendekatan participatory action research (PAR). Akan tetapi secara kolektif penelitian sebelumnya nampaknya belum menyentuh kesadaran akan kuasa (power) sehingga terkesan penelitian ini kemudian hanya mengantarkan penderita HIV AIDS (ODHA) tidak secara utuh menjadi subyek kesadaran mereka sendiri dan sekaligus subyek gerakan aksional mereka sendiri.

Berbeda dari riset sebelumnya, riset ini akan menelisik persoalan kolektif para perempuan muslimah ODHA di Kebumen. Asumsinya adalah bahwa penguatan secara partisipatoris terhadap perempuan muslimah ODHA akan melahirkan kesadaran kolektif

\footnotetext{
${ }^{1}$ Dinas Kesehatan Kabupaten Kebumen, Analisa Situasi HIV AIDS Kabupaten Kebumen, Juni 2018.

${ }^{2}$ Nurhasanah dkk.,Konsep Diri Orang dengan HIV dan AIDS (ODHA) yang Menerima Label Negatif dan Diskriminasi dari Lingkungan Sosial.Jurnal Psikologia-Online, Volume 7, Nomor 1, hal.29-440, Tahun 2012.

3 Surahman Wahyu, dkk., Konsep Diri dan Masalah Yang Dialami Orang Terinfeksi HIV/AIDS, Artikel dalam jurnal Konselor, Volume 1, Nomor 1, Januari 2012, hal. 1-12, Tahun 2012

${ }^{4}$ Awatiful Azza, dkk., Pemberdayaan Kesehatan dan Ekonomi Perempuan Penderita HIV/AIDS Melalui Life Skill Education, Artikel dalam Jurnal Ners, Volume 10, Nomor 1, April 201, hal. 183-188
} 
mereka melawan stigma dan diskriminasi, melawan konsep diri negatif, dan membuka ruang kemandirian dan produktivitas mereka sendiri di tengah masyarakatnya. Riset mencoba membangun kesadaran kuasa (power) perempuan muslimah ODHA, yang bangunannya merupakan wujud refleksi dari kesadaran milik mereka sendiri. Dari kesadaran ini kemudian merambat menjadi gerakan aksional mereka untuk membentuk kemandirian dan berkiprah mereka.

Riset ini riset transformatif yang memiliki tujuan untuk mengupayakan penguatan perempuan muslimah ODHA di Kebumen yang mampu mandiri dan berkiprah. Dengan kata lain, riset ini mencoba membangun pendekatan participatory action research (PAR) dengan menempatkan mereka sebagai subyek sadar diri dan sekaligus subyek gerakan aksional. Riset ini bersifat sustainable dan mencoba membangun kesadaran kolektif mereka secara partisipatoris dan mengupayakan langkah aksional mereka dalam mengupayakan penyelenggaraan kegiatan dari dan bagi ODHA sendiri. Tujuan akhir riset ini adalah adanya perempuan muslimah ODHA yang mampu mandiri dan berkiprah, yang memiliki daya milik, daya kelola, dan daya guna. Adapun hasil diharapkan adalah (1)mengupayakan hilangnya stigma dan diskriminasi terhadap perempuan muslimah ODHA yang bertumpu pada kekuatan (power) mereka sendiri, (2)adanya kesadaran sendiri yang berkembang menjadi gerakan aksional mereka melalui kegiatan yang mandiri dan produktif mereka.

Pada tahap awal riset ini akan berkonsentrasi pada upaya penguatan kesadaran perempuan muslimah ODHA akan eksistensi mereka sendiri beserta potensi yang dimiliki. Penguatan ini dikandung maksud juga sekaligus untuk mengikis konsep diri negatif mereka sendiri dan melawan stigma dan diskriminasi. Konsep membangun kepercayaan diri (selfconvidence) menjadi pokoknya sedemikian sehingga terbangun tekad untuk mandiri dan berkiprah.

\section{GAMBARAN KEGIATAN}

Kegiatan untuk upaya penguatan bagi perempuan muslimah ODHA dilaksanakan dengan gambaran skema berupa: (1) kegiatan diskusi dan semacam focused group discussion (FGD) untuk membangun keterbukaan dan kesadaran mereka sebagai pribadi dan komunitas yang memiliki kekuatan, melalui knowledge sharing dan diskusi hasil temuan, dan periset lebih bertindak sebagai fasilitator, (2) kegiatan inventarisasi permasalahan yang mereka hadapi, sekaligus inventarisasi tujuan dan harapan mereka, (3) penyusunan pihak mitra kerja (stakeholders) yang mereka pandang dapat membantu mereka untuk merealisasikan rencana, dan (4) penyusunan rencana kegiatan aksional. Sesuai dengan kesepakatan, pertemuan juga 
dapat menghadirkan pihak mitra pegiat HIV AIDS yang mereka pandang dapat membantu. Para pegiat ini berfungsi untuk memperkuat rencana dan langkah aksional mereka. Rangkaian kegiatan di atas akan dilakukan dalam beberapa kali pertemuan selama Mei-Juni 2018.

\section{TEMUAN PENELITIAN}

\section{Knowledge Sharing}

Riset mengawali dengan berkoordinasi dengan Sungkono ${ }^{5}$, seorang pegawai di lingkungan Pemerintah Kabupaten Kebumen untuk mendapatkan akses data kekinian ODHA di Kebumen. Diperoleh data per Mei 2018 bahwa jumlah ODHA-hidup sejumlah 1.042 orang dan ODHA-meninggal 398 orang. Ketika disinggung apakah perlu adanya penguatan bagi perempuan muslimah ODHA di Kebumen, Sungkono setuju dengan dalih bahwa persoalan mereka juga menjadi bagian dari tanggungjawab sosial kita.

Ketika data tersebut di atas dikonfirmasikan pada Saskia pegawai rumah sakit di Kebumen yang banyak mengurusi HIV AIDS, dia membenarkan. Bahkan dia menambahkan bahwa jumlah tersebut sangat mungkin akan bertambah dengan semakin banyak ditemukannya kasus baru HIV AIDS. Saskia berharap banyak muncul langkah konkret dari banyak mitra untuk membantu menyelesaikan permasalahan mereka. Ketika ditanyakan apakah sudah ada upaya penguatan khusus bagi perempuan muslimah ODHA, Saskia menggelengkan kepala. Dia mengatakan bahwa di Kebumen hanya ada Kelompok Dukungan Sebaya (KDS) yang dibentuk dan tidak bersifat mewadahi para ODHA. KDS hanya menjadi semacam media semacam peer group saja bagi ODHA baru, dan keberadaannya pun sebatas adanya dukungan dari dana Global Fund. Ketika ditanyai apakah perlu adanya upaya penguatan bagi perempuan muslimah ODHA sendiri, Saskia setuju sekali.

Pertemuan dengan Saskia menjadi tahap awal. Diskusi dengan Saskia berkait dengan perlunya upaya penguatan bagi perempuan muslimah ODHA. Diskusi ini menentukan dari mana sebaiknya upaya penguatan dimulai, kemudian metode apa yang dipakai, dan siapa saja yang menjadi informan kunci. Saskia menyarankan agar upaya dimulai dari para perempuan muslimah ODHA yang aktif datang ke rumah sakit. Metodenya mempergunakan wawancara sharing dan diskusi. Adapun perempuan muslimah ODHA yang dijadikan informan kunci adalah Bellani, Hernia, dan Venusa, dan nantinya akan dikembangkan dengan model snowball informants.

\footnotetext{
${ }^{5}$ Nama samaran, dan seluruh nama asli informan dalam riset ini diganti dengan nama samara.
} 
Komunikasi pertama kali dengan perempuan muslimah ODHA dilakukan dengan informan kunci bernama Bellani (24tahun). Dia adalah seorang perempuan muda, IRT, yang tinggal di wilayah Kecamatan Wetanan, sebuah kecamatan di timur kota Kebumen. Tarno suami Bellani bekerja di Jakarta dua bulan sekali pulang, dan ini membuat Bellani banyak tinggal bersama ayah, ibu, adiknya, dan anaknya di rumah orangtuanya sendiri. Dia tertular HIV AIDS dan menjadi ODHA dari almarhum Fajar mantan suaminya. Menikah dengan Fajar, dia sempat melahirkan anak, namun 3 bulan kemudian anaknya meninggal terindikasi terinfeksi HIV/AIDS. Sekarang dia sudah menikah lagi dengan Tarno dan sudah memiliki anak umur 2 tahun yang sehat melalui proses kelahiran caesar dan tidak menyusu ASI.

Ketika mendikusikan tentang apakah perlu dibuat upaya penguatan dari dan bagi perempuan muslimah ODHA, Bellani setuju dan mendukung saja, bahwa setidaknya mereka akan dapat saling bertemu dan saling menguatkan dengan harapan akan tumbuh rasa percaya diri dan tekad menjalani hidup yang lebih mandiri dan produktif. Dia mengajukan usulan agar dapat diselenggarakan kegiatan semacam pengaiian keIslaman bersama para perempuan muslimah ODHA untuk memperkuat mental mereka. Selain itu dia juga mengharap kegiatan ekonomi produktif untuk mereka agar mereka juga dapat menghasilkan uang untuk mereka sendiri, keluarganya, dan sekaligus untuk mengurangi rasa tertekan dalam diri mereka. Tentang bentuk kegiatan ekonomi, dia belum mempunyai gambaran kegiatannya. Untuk kegiatan produktif, dia mengharap kegiatan juga akan melibatkan perempuan non-muslimah ODHA. Ketika mendiskusikan seputar bagaimana pergaulan sosialnya, dia masih takut stigma dan diskriminasi masyarakat. Dari diskusi dan sharing bersamanya, dia merekomendasikan untuk dapat mengkomunikasikan juga bersama teman sebayanya, yaitu, Rosa, Tri, dan Sari. Ketika disodori pertanyaan yang sama, semuanya menyatakan setuju dan senang, asalkan bersama Bellani.

Komunikasi kedua dilakukan dengan informan kunci bernama Hernia (28 tahun). Dia tinggal di wilayah Kecamatan Gunungan dari kota Kebumen ke arah utara. Dia IRT dan janda ditinggal mati Tono mantan suaminya. Dia tertular HIV AIDS oleh Tono dan kemudian menjadi ODHA. Dia pernah mempunyai anak dan meninggal pada usia 3 bulan. Dia kini banyak tinggal di rumah orangtuanya. Ketika diajak mendikusikan tentang apakah perlu dibuat upaya penguatan dari dan bagi ODHA, dia setuju dan mendukung saja. Dia senang apabila diselenggarakan kegiatan pengaiian bersama perempuan muslimah ODHA. Selain itu, dia juga mengharap ada kegiatan produktif untuk mereka agar mereka juga dapat menghasilkan uang tambahan untuk mereka sendiri, sekaligus untuk mengurangi rasa tertekan sebagai ODHA. Tentang bentuk kegiatan ekonomi, dia ikut saja. Ketika mendiskusikan seputar pergaulan 
sosialnya, dia masih takut stigma dan diskriminasi masyarakat. Atas rekomendasi Hernia, komunikasi dengan bahan diskusi yang sama kemudian berkembang juga bersama teman sebaya Hernia, yaitu, Dewita, Pinky dan Emita. Ketiga orang senang dan setuju saja ketika disodori bahan diskusi yang sama dengan Hernia.

Komunikasi ketiga dilakukan dengan informan kunci bernama Venusa (26 tahun), seorang ibu rumah tangga muda. Dia tinggal bersama Samsu suaminya di wilayah Kecamatan Sisiran di wilayah selatan Kabupaten Kebumen. Dia dulu pernah sebentar menjadi seorang wanita pekerja seks tak-langsung (WPS-TL). Ketika dia diajak berbincang santai tentang apakah perlu dibuat upaya penguatan dari dan bagi ODHA, pada prinsipnya dia setuju. Dia setuju dan sangat senang apabila ada kegiatan pengajian dan kegiatan ekonomi untuk perempuan muslimah ODHA di Kebumen. Bahkan dia siap mengajak teman-teman sesama perempuan ODHA. Soal bentuk kegiatannya, dia ikut saja. Ketika ditanya tentang bagaimana pergaulan sosialnya, dia sudah tidak terlalu memasalahkan stigma dan diskriminasi masyarakat. Dari informasi Venusa, kemudian komunikasi seputar penguatan ini berkembang juga bersama teman sebaya Venusa, yaitu, Gabriella dan Helena. Kedua perempuan ODHA ini setuju saja ketika disodori pertanyaan yang sama.

Dari pertemuan intensif selama Juni 2018 bersama Bellani, Hernia, dan Venusa, dapat ditemukenali persoalan yang sebenarnya dihadapi para perempuan ODHA. Dari keseriusan, mimik, dan ekspresi jawaban sepanjang berdiskusi, persoalan ketakutan terhadap stigma dan diskriminasi orang lain masih dominan. Bahkan Hernia dan Venusa mulai mengubah penampilannya dengan berjilbab semenjak dirinya positif tertular HIV AIDS dan menjadi ODHA dengan tujuan untuk mengurangi rasa takutnya dan menghindari stigma dan diskriminasi masyarakat.

Selanjutnya diadakan pertemuan knowledge sharing bersama Bellani, Hernia, dan Venusa. Pertemuan ini juga menghadirkan Saskia yang sudah akrab dengan mereka bertiga. Ketiga informan kunci ini dipandang cukup untuk mewakili sejumlah perempuan muslimah ODHA di Kebumen beserta gambaran umum persoalan yang mereka hadapi dan harapan-harapan mereka. Diskusi lanjutan mencoba membangun langkah-langkah apa saja yang perlu dilakukan kemudian bagi kepentingan para perempuan muslimah ODHA di Kebumen. Selain itu, kegiatan juga mencoba menginventarisir nama-nama pegiat HIV AIDS Non-ODHA maupun ODHA yang dipandang dapat dihubungi untuk ngobrol, rasan-rasan, dan mendukung langkahlangkah upaya penguatan bagi perempuan muslimah ODHA. Dari hasil diskusi, mereka menyepakati perlunya menghubungi Bill, Max, Listiya, dan Metro, yang semuanya sudah dikenal mereka sebagai pegiat HIV AIDS yang cukup aktif. 
Selanjutnya pada bulan Juni 2018, riset dikembangkan dengan pegiat HIV AIDS NonODHA dan ODHA sesuai rekomendasi para informan kunci di atas. Yang pertama adalah Bill (44 tahun), seorang suami, swasta, dan memiliki kecenderungan heteroseksual. Dia tinggal di wilayah Kecamatan Sabranglor di sebelah timur kota Kebumen. Rumahnya sederhana. Dia tinggal bersama istri dan 2 anaknya yang sudah remaja. Ketika ditanya tentang perilaku heteroseksualnya, dia belum terbuka dengan keluarganya. Ketika diajak diskusi tentang apakah Bill siap apabila para perempuan muslimah ODHA meminta bantuannya, dia menyatakan bahwa pada prinsipnya dia siap walaupun itu juga tergantung pada kemauan dan tekad para perempuan muslimah ODHA. Bahkan dia juga siap membantu mengajak sejumlah perempuan muslimah ODHA yang ia kenal baik untuk ikut bergabung nantinya.

Selanjutnya komunikasi intensif dilakukan pada Juni 2018 dengan Max (45 tahun) seorang pegiat HIV AIDS, non-ODHA. Max setuju dengan upaya penguatan bagi para perempuan muslimah ODHA melalui kegiatan keagamaan dan kegiatan ekonomi produktif. Bahkan dia siap mencarikan sosok siapa yang sebaiknya mengisi pengajian keIslaman untuk kalangan perempuan muslimah ODHA. Walaupun demikian, dia tidak terlalu optimis apakah para ODHA dapat istiqamah dengan kegiatan mereka sendiri. Pada prinsipnya dia tetap siap membantu, bahkan dia siap membantu mengajak sejumlah perempuan muslimah ODHA untuk mendukung dan bergabung dengan kegiatan yang direncanakan.

Kemudian Max mencoba membantu dengan menghubungi Listiya dan Metro. Listiya (34 tahun) adalah pegiat HIV AIDS, ODHA, pengusaha kecil. Sedangkan Metro (35 tahun) itu seorang ODHA, suami Listiya. Kemudian Max, Listiya, dan Metro bertemu dan berdiskusi di rumah Max. Hasil diskusi santai bersama Max, Listiya, dan Metro adalah bahwa perlu adanya upaya penguatan bagi perempuan muslimah ODHA. Mereka senang jika terdapat penguatan mental melalui kegiatan pengajian keIslaman. Mereka juga setuju dengan upaya kegiatan ekonomi produktif, seperti menjahit, membuat makanan kecil, dan lainnya. Apalagi jumlah ODHA semakin bulan semakin bertambah, dan ketergantungan pada bantuan Global Fund harus diimbangi dengan upaya sendiri. Namun demikian, baik Max dan Metro merasa kurang optimis. Hanya Listiya merasa cukup optimis bahwa perempuan muslimah ODHA dapat berkiprah melalui kegiatan ekonomi produktif, dan dia siap membantu upaya penguatan ekonomi produktif. Mereka sepakat bahwa para ODHA masih membutuhkan bantuan para pegiat HIV AIDS untuk mengupayakan sejumlah kegiatan bagi para perempuan muslimah ODHA sendiri. 


\section{Diskusi Hasil Temuan}

Sebelum mendiskusikan hasil temuan lebih jauh, di sini dibuat susunan sebagai berikut.

1. Hasil temuan dengan informan Sungkono, Saskia, Bellani, Hernia, dan Venusa di sini disebut sebagai Hasil Temuan A.

2. Hasil temuan dengan informan Max, Bill, Listiya, dan Metro di sini disebut sebagai Hasil

\section{Temuan B.}

3. Kelompok Sungkono, Saskia, Bellani, Hernia, dan Venusa, di sini disebut Kelompok 1.

4. Kelompok Max, Bill, Listiya, dan Metro di sini disebut Kelompok 2.

5. Hasil Temuan A didiskusikan dalam Kelompok 2, dan sebaliknya Hasil Temuan B didiskusikan dalam Kelompok 1.

\section{Tabel 1. Hasil Temuan B}

\begin{tabular}{|c|c|c|}
\hline \multirow{2}{*}{ Nama } & \multicolumn{2}{|c|}{ Situasi } \\
\hline & Personal & Sosial \\
\hline 1. Sungkono & $\begin{array}{l}\text { Non-ODHA, setuju dengan upaya } \\
\text { penguatan bagi perempuan muslimah } \\
\text { ODHA }\end{array}$ & Secara umum siap membantu \\
\hline 2. Saskia & Non-ODHA, setuju & Secara umum siap membantu \\
\hline 3. Bellani & ODHA, setuju & $\begin{array}{l}\text { Masih takut stigma dan diskriminasi } \\
\text { masyarakat, siap mengajak teman sebayanya }\end{array}$ \\
\hline 4. Hernia & ODHA, senang dan setuju & $\begin{array}{l}\text { Masih waswas stigma dan diskriminasi } \\
\text { masyarakat, siap mengajak teman sebayanya }\end{array}$ \\
\hline 5. Venusa & ODHA, setuju & $\begin{array}{l}\text { Tidak ada masalah berarti, siap mengajak } \\
\text { teman sebayanya }\end{array}$ \\
\hline
\end{tabular}

\section{Tabel 2. Hasil Temuan B}

\begin{tabular}{|c|c|c|}
\hline \multirow{2}{*}{ Nama } & \multicolumn{2}{|c|}{ Situasi } \\
\hline & Personal & Sosial \\
\hline 1. Bill & $\begin{array}{l}\text { Non-ODHA, heterosekual, setuju } \\
\text { dengan upaya penguatan bagi } \\
\text { perempuan muslimah ODHA, kurang } \\
\text { optimis terhadap ODHA sendiri } \\
\text { kurang optimis }\end{array}$ & $\begin{array}{l}\text { Perilaku seksualnya masih tertutup dengan } \\
\text { keluarganya, siap membantu mengajak } \\
\text { perempuan muslimah ODHA yang dia kenal. }\end{array}$ \\
\hline 2. Max & Non-ODHA, setuju, kurang optimis & $\begin{array}{l}\text { Siap membantu mengajak perempuan } \\
\text { muslimah ODHA yang dia kenal, siap } \\
\text { mencarikan sosok pengisi pengajian }\end{array}$ \\
\hline 3. Listiya & Setuju, cukup optimis & $\begin{array}{l}\text { Tidak ada masalah berarti, siap membantu } \\
\text { terkait kegiatan ekonomi produktif }\end{array}$ \\
\hline 4. Metro & Setuju, kurang optimis & $\begin{array}{l}\text { Tidak ada masalah berarti, siap membantu } \\
\text { secara umum }\end{array}$ \\
\hline
\end{tabular}


Pada Juni 2018, Kelompok 1 (Sungkono, Saskia, Bellani, Hernia, Venusa) disodori Hasil Temuan B (Max, Bill, Listiya, dan Metro), dan diperoleh kesimpulan bersama bahwa:

1. Sebaiknya upaya penguatan perempuan muslimah ODHA itu melibatkan para pegiat HIV AIDS. Max, Bill, Listiya, dan Metro perlu dilibatkan serius dalam upaya penguatan bagi perempuan muslimah ODHA.

2. Listiya yang berprofesi sebagai pengusaha kecil dapat dimintai bantuan untuk arahan kegiatan ekonomi produktif bagi mereka.

3. Max dan Bill dapat dimintai bantuan untuk menghadirkan kyai/dai/ustadz/ustadzah untuk mengisi kegiatan pengajian serta teman-temannya perempuan muslimah ODHA.

4. Bellani dan Hernia siap menjadi duta Kelompok 1 dan bertemu dengan Kelompok 2 untuk berdikusi lebih lanjut.

Selanjutnya Juni 2018, Kelompok 2 (Bill, Max, Listiya, Metro) disodori Hasil Temuan A (Sungkono, Saskia, Bellani, Hernia, Venusa), dan diperoleh kesimpulan bersama bahwa:

1. Sungkono dan Saskia sebagai pihak terkait pemerintah dan rumah sakit perlu membantu upaya penguatan bagi perempuan muslimah ODHA dengan membantu menyiapkan lokasi kegiatan pengajian keIslaman di kompleks rumah sakit atau di tempat lain.

2. Bellani, Hernia, dan Venusa harus dapat menjadi motor utama merangkul para perempuan muslimah ODHA lainnya untuk segera merealisasikan rencana kegiatan-kegiatannya.

3. Max dan Bill siap menjadi duta Kelompok 2 untuk bertemu dengan Kelompok 1 untuk berdiskusi lebih lanjut.

Pada Juni 2018 kesimpulan-kesimpulan di atas disepakati bersama, bahwa:

1. Bellani, Hernia, Venusa, Max, dan Bill ditunjuk untuk merealisasikan rencana kegiatan pengajian keIslaman dan atau kegiatan ekonomi produktif, sekaligus untuk mengundang para perempuan muslimah ODHA dan atau lainnya yang dipandang perlu, termasuk mengaktivasi Kelompok Dukungan Sebaya (KDS). Kegiatan diharapkan dapat direalisiasikan September 2018, dengan menghadirkan perempuan muslimah ODHA sekitar 100 orang.

2. Kegiatan akan melibatkan tokoh-tokoh masyarakat yang memiliki perhatian terhadap ODHA, khususnya perempuan muslimah ODHA, seperti tokoh dari Nahdlatul Ulama, Muhammadiyah, Kementerian Agama, Pemerintahan Kabupaten Kebumen, dan lainnya. 


\section{PEMBAHASAN}

Riset upaya penguatan perempuan muslimah ODHA di Kebumen ini merupakan satu bentuk riset partisipatori berbasis komunitas atau Community-Based Participatory Research (CBPR), yaitu, "a collaborative approach to research that equitably involves all partner in research process and recognizes the unique streghths that each brings. CBPR begins with a research topic of importance to the community with the aim of combining knowledge and action for social change to improve community" . CBPR juga dapat didefinisikan sebagai "as systematic inquiry, with the collaboration of those affected by the issue being studied, for purposes of education and taking action or affecting change"

Sebagai riset partisipatori, riset berusaha untuk membangun lebih lanjut tentang model Participatory action research (PAR) sebagaimana dijelaskan Peter-Khanlou dalam tulisan Julie Watters, Savanna Comeau, dan Gayle Restall, bahwa PAR sebagai "combines two different approaches: participatory research and action research' ${ }^{\text {'8 }}$.

Terkait dengan terma 'participatory', Biggs dalam tulisan Andrea Cornwall dan Rachel Jewkes membagi empat model partisipasi, yaitu, contractual, consultative, collaborative, dan collegiate

9. Riset ini termasuk riset model collaborative dimana antara periset dengan komunitas bekerja bersama dalam upaya awal pemberdayaan ODHA, dengan skema kegiatannya banyak didesain, diinisiasi, dan dikelola oleh periset. Namun dengan keterbatasan periset, riset ini tetap memberikan ruang collegiate dimana komunitas diberikan ruang apresiasi dan kontrol mutualistik di dalam proses riset. Dengan kata lain, sebuah riset pemberdayaan perempuan muslimah ODHA membuka ruang kolaboratif-kolegial antara periset dengan komunitas agar partisipasi dapat berlangsung maksimal dan pemberdayaan sebagai keniscayaan aksi perubahan sosial yang diharapkan dapat terjadi lebih alamiah. Inilah model riset yang disebut Agus Afandi, dkk. sebagai riset transformatif dimana terjadi proses kerja prinsipil dengan munculnya kesadaran kritis, dialog kritis, kemandirian, dan kolaborasi di dalam komunitas ${ }^{10}$.

Dari uraian hasil riset di atas dapat diketahui bahwa riset ini sudah melahirkan kesadaran kritis, dialog kritis, dan kolaborasi di dalam komunitas perempuan muslimah

${ }^{6}$ Meredith Minkler dan Nina Wallertein.Community-Based Participatory Research for Health.San Fransisco, CA: Jossey-Bass Inc., 2003, hal. 4.

7 Lawrence Green, et.al. "Appendix C: Guideline for Participatory Research in Health Promotion”, dalam Meredith Minkler dan Nina Wallertein. Community-Based Participatory Research for Health.San Fransisco, CA: Jossey-Bass Inc., 2003, hal. 419 .

8 Julie Watters, Savanna Comeau, Gayle Restall, Participatory Action Research.Department of Occupational Therapy, School of Medical Rehabilitation, University of Manitoba, 2010, hal. 5.

${ }^{9}$ Andrea Cornwall dan Rachel Jewkes, What Is Participatory Research?, dalam Jurnal Social Science and Medicine, Volume 41, Nomor 12, 1995, hal.1667-1676

10 Agus Afandi, dkk. Modul Riset Transformatif, Sidoarjo, Dwi Putra Pustaka Jaya, 2017. Lihat Ahmad Mahmudi, dkk. (ed.), Gamang, Lembaga Pendidikan Islam Menghadapi Perubahan Sosial, Seri Penerbitan Hasil Penelitian Aksi Partisipatif, Direktorat Pendidikan Tinggi Islam Direktorat Jenderal Pendidikan Islam Departemen Agama RI, Cetakan 1, 2008 
ODHA sekaligus pegiat HIV AIDS di Kebumen. Gagasan untuk membuat rencana kegiatan dan berupaya merealisasikan rencana kegiatan mereka sendiri sebagai suatu bentuk kemandirian mereka nampaknya sudah menemukan modal dan sekaligus jalan masuk, sehingga pada waktu yang akan datang memang perlu dilakukan riset kolaboratif berkelanjutan dengan model participatory action research (PAR). Sebuah manajemen pemberdayaan yang bersifat transformatif menjadi keniscayaan proses sustainable pemberdayaan dengan mempergunakan model PAR. Meskipun riset ini dapat dikatakan sebagai sebuah riset awal, akan tetapi gambaran upaya penguatan perempuan muslimah ODHA di Kebumen sudah menunjukkan titik terang bagi upaya-upaya berikutnya. Lebih jauh lagi, bahwa model PAR nampaknya memang masih sangat layak menjadi model pendekatan bagi riset transformatif lanjutan dan tentunya bagi riset-riset yang sejenis.

Terkait dengan pilihan kegiatan, kegiatan pengajian keIslaman dan kegiatan ekonomi produktif, menunjukkan bahwa dominasi rasa takut, stigma, dan diskriminasi masih menjadi momok tersendiri bagi kalangan perempuan muslimah ODHA, dan juga persoalan ekonomi dan survival. Pengajian keagamaan Islam rupanya menjadi pilihan sekaligus jalan keluar mereka untuk mengikis rasa takut, membangun kepercayaan diri, dan melawan stigma dan diskriminasi, selain untuk mempertebal keyakinan mereka sendiri terhadap Allah Ta'ala. Sedangkan pilihan kegiatan ekonomi produktif nampaknya menjadi pilihan untuk menunjukkan eksistensi mereka, sekaligus sebagai bagian dari ikhtiar survival mereka menghadapi kenyataan hidup. Kedua pilihan mereka ini tentunya sangat menarik, sebab kegiatan pengajian lebih bersifat inner, batiniyah, dan olah jiwa, dan kegiatan ekonomi produktif lebih bersifat outer, lahiriyah, dan olah raga dan pikiran.

\section{PENUTUP}

Riset pendampingan transformatif ini memang masih pada tahapan perencanaan kegiatan, baik kegiatan pengajian maupun kegiatan ekonomi produktif, meskipun hasilnya sudah cukup menggembirakan. Kesadaran kritis pada perempuan muslimah ODHA sudah muncul. Bahkan mereka sudah memiliki keberanian untuk membangun rencana-rencana aksi untuk membangun eksistensi mereka sendiri.

Luasnya wilayah Kabupaten Kebumen, sebaran perempuan muslimah ODHA, dan masih rendahnya intensitas pertemuan nampaknya cukup menjadi kendala. Kendala lain berupa dominannya rasa takut terhadap stigma dan diskriminasi. Oleh karenanya, pengawalan intensif atas upaya-upaya aksional lanjutan penting dilakukan pada riset berikutnya agar tujuan 
memberdayakan dan memperkuat perempuan muslimah ODHA di Kebumen menuju perempuan muslimah ODHA yang siap mandiri dan siap berkiprah di tengah masyarakatnya benar-benar dapat terwujud. Upaya ini nampaknya tetap masih memerlukan keterlibatan para pegiat HIV AIDS.

Saran rekomendasi dari riset ini adalah perlu dan pentingnya manajemen pemberdayaan perempuan muslimah ODHA secara massif dan komprehensif yang menggandeng bersama secara partisipatif-aktif. kalangan akademisi, agamawan, dan pemangku kebijakan dalam upaya-upaya penguatan perempuan muslimah ODHA di Kebumen melalui model PAR.

\section{REFERENSI}

Agus Afandi, dkk. 2017. Modul Riset Transformatif, Sidoarjo, Dwi Putra Pustaka Jaya

Ahmad Mahmudi, dkk. (ed.), 2008. Gamang, Lembaga Pendidikan Islam Menghadapi Perubahan Sosial, Seri Penerbitan Hasil Penelitian Aksi Partisipatif, Direktorat Pendidikan Tinggi Islam Direktorat Jenderal Pendidikan Islam Departemen Agama RI, Cetakan 1

Andrea Cornwall dan Rachel Jewkes, 1995. What Is Participatory Research?, Jurnal Social Science and Medicine, Volume 41, Nomor 12

Awatiful Azza, dkk., 2010. Pemberdayaan Kesehatan dan Ekonomi Perempuan Penderita HIV/AIDS Melalui Life Skill Education, Jurnal Ners, Volume 10, Nomor 1, April 2010

Julie Watters, Savanna Comeau, dan Gayle Restall, 2010. Participatory Action Research. Department of Occupational Therapy, School of Medical Rehabilitation, University of Manitoba, 2010

Lawrence Green, et.al. 2003. "Appendix C: Guideline for Participatory Research in Health Promotion", dalam Meredith Minkler dan Nina Wallertein. Community-Based Participatory Research for Health. San Fransisco, CA: Jossey-Bass Inc.

Meredith Minkler dan Nina Wallertein , 2003. Community-Based Participatory Research for Health.San Fransisco, CA, Jossey-Bass Inc.

Nurhasanah dkk., 2012. Konsep Diri Orang dengan HIV dan AIDS (ODHA) yang Menerima Label Negatif dan Diskriminasi dari Lingkungan Sosial, Jurnal Psikologia-Online, Volume 7, Nomor 1, hal.29-440, Tahun 2012.

Surahman Wahyu, dkk., 2012. Konsep Diri dan Masalab Yang Dialami Orang Terinfeksi HIV/AIDS, Jurnal Konselor, Volume 1, Nomor 1, Januari 2012, hal. 1-12, Tahun 2012.

http://kpa.kebumenkab.go.id 